\title{
Gender Differences in Feeding, Care, Support and Nutritional Status of Children in the Rural Area of Kaski District, Nepal.
}

\author{
${ }^{1}$ Basundhara Shrestha, ${ }^{1}$ Dipendra Kumar Yadav
}

${ }^{1}$ School of Health and Allied Sciences, Pokhara University, Nepal

\begin{abstract}
The girl child faces the neglect of the family in the form of a failure to provide her the basic necessities of life in terms of food, clothing, love, shelter, supervision, education and medical care. Differential treatment of the boys and girls within families can be attributed to the social religious, cultural and economic returns that sons provide to their parents relative to daughters. Objective of the study was to assess the gender differences in feeding, care, support and nutritional status of children in the rural area of Kaski district, Nepal. A cross sectional study was carried out among the 456 children of 0-23 months from four VDCs of Kaski district. Data were collected using cluster random sampling. After obtaining the oral consent from the mothers and then data were collected in a pre-tested, pre designed, structured questionnaire by interview technique. In this study half of the respondents initiated breast milk within one hour after birth. Among them, more male children were received breast milk than female children. Nearly all (98.7\%) of female child were fed colostrums milk. More than half (53.6\%) of the respondents (male $54.4 \%$ and female $52.9 \%$ ) were feeding breast milk more than nine times in 24 hours. Higher proportions of male children were exclusively breastfed than female children. Similarly higher percentages of male children were fed complementary food on timely than female children. The frequency of complementary feeding was less than four times for both children. During child illness most of the respondents went to hospital and almost all children got vaccines and vitamin A. Female appeared slightly more likely to be stunted than male. $19.2 \%$ male and $13.1 \%$ female were underweight and the proportion of wasted were nearly same in both male and female. There were no much differences among both the gender regarding feeding practice, care and support.
\end{abstract}

Keywords: Gender differences in feeding; Care; Nutritional status of children; Rural area

Corresponding address: Dipendra Kumar Yadav, PhD, School of Health and Allied Sciences, Pokhara University, E-mail: dipendrayadavph@gmail.com

\section{INTRODUCTION}

Gender refers to the socially constructed characteristics of women and men such as norms, roles and relationships of and between groups of women and men. It varies from society to society and can be changed. ${ }^{1}$ Gender discrimination is meant for women, because females are more often the victims. Denial of equality, rights and opportunity and supplement in any form on the basis of gender is gender discrimination. Gender discrimination is due to the attitude and behavior of the society towards the girl child. The girl child faces the neglect of the family in the form of a failure to provide her the basic necessities of life in terms of food, clothing, love, shelter, supervision, education and medical care. Differential treatment of the boys and girls within families can be attributed to the social religious, cultural and economic returns that sons provide to their parents relative to daughters. ${ }^{2}$

Care and support describes the help to live as well as possible without any illness or disability that you may have, so that you can stay healthy and remain independent for longer. ${ }^{3}$ Appropriate feeding practice is very important for normal growth and development of infant and young children. ${ }^{4}$ These practices include initiation of breastfeeding within 1 hour of birth; exclusive breastfeeding for the first 6 months of life; and addition of timely, appropriate, and adequate family foods for complementary feeding after 6 months along with continued breastfeeding. WHO recommends that exclusive breastfeeding for the first six months is the most appropriate infant feeding practice. ${ }^{5,6,7}$

Nutrition has a great impact in child's life and feeding practices has direct impact on the nutritional status and well. ${ }^{8}$ Gender differences are as old as human culture arising from the biological differences early human males and females. ${ }^{9}$ Gender differentials in nutritional status are reported during infancy, with discriminatory breastfeeding and supplementation practices. Infant girls are breastfed less frequently, for shorter duration, and over shorter periods than boys. Girls and women face nutritional discrimination within the family, eating last and least resulting in nutritional deprivement, leading malnourishment. ${ }^{9}$ Malnutrition is a serious public health problem which, occurring in a girl child, has grave aftermaths. ${ }^{10}$ This study was carried out to assess the gender differences in feeding practices, care and support during illness by their mother and nutritional status of children

\section{METHODS}

A cross sectional study was conducted in the rural area of Kaski district from June 2016 to December 2016. Cluster random sampling technique was used for the selection of participants. In cluster random sampling VDCs were chosen under the electoral constituency of Kaski district. Kaski 
district has four electoral constituents. Those VDCs which were far from Pokhara municipality and time required whole day to reached at VDCs were excluded because of our time constant. In electoral constituency 2 and 3, there were all urban area under municipality and these areas were excluded. In electoral constituents 1 and 4, one VDC from each constituency and total two VDCs (Puranchaur \& Rupakot) were randomly chosen from the list of remaining VDCs. From both VDCs all wards were chosen and making 18 clusters. Our study sample size was not fulfilled from these VDCs then, I took sample from nearby VDCs (Deurali and Sardikhola). Regarding selection for ward 'spin the pencil technique' was used to identify the starting point of the household and participant. According to this technique at the centre of sample area pencil was spinned and the direction pointing by the tip of pencil was chosen for the selection of the participants.

Participants were the Mothers who had at least one child less than two years of age. The required sample size was 456 . $\mathrm{n}=(\mathrm{z} 2 \mathrm{pq} / \mathrm{d} 2)$ Where, $\mathrm{n}=$ required sample size, $\mathrm{d}=$ precision $(5 \%), p=$ expected proportion (prevalence $45.3 \%)^{2}$, Design effect $=1.2, z=$ statistic at $95 \%$ level of confidence, Design effect $=1.2$, Then, sample size was $=80 * 1.2=456$

At first formal permission was taken from respective authority. Informed consent was taken from participants before data collection. Participants were made clear about the purpose of the study, benefits of the study to them and assuring them about the confidentiality of the information. The interview was conducted considering comfort for the participants such as dominating voice and leading questions were not asked. Face to face interview and body measurement of their children was carried out. Structured interview schedule was used for data collection. Weight, height and upper arm circumference of the children were measured by using salter hanging scale, stature meter and Shakir tape.

Before commencing data collection for this study, a proposal was submitted to the Institutional Review Committee (IRC) Pokhara University and took the ethical clearance. Permission was taken from DPHO and DDC, Kaski. From this research respondent got the appropriate information about timing, quality, quantity and nutritional status of their children. Those who failed to provide consent for any reason were excluded from the study. Data was entered in EpiData 3.1 and all the entry data was transferred into SPSS version 20 for the further analysis. Data were analyzed using appropriate statistical tests.

\section{RESULTS}

Table no. 1 shows the socio-demographic information of the respondents. In this study proportion of male and female were equal and $43.6 \%$ children were $0-6$ months of age and $56.4 \%$ children were $7-23$ months of age. Most (89\%) of the respondents reported that they follow Hinduism. More than half $(57.9 \%)$ of the family type were single. Most (79.6\%) of the respondents had 2 or less children. Main source of income in the family was job (all type).

Table 1: Socio-demographic characteristics of the study participants

\begin{tabular}{|l|l|l|}
\hline \multicolumn{1}{|c|}{ Background characteristics } & Frequency(456) & Percentage (\%) \\
\hline Gender & \multicolumn{2}{|l|}{} \\
\hline Male & 288 & 50.0 \\
\hline Female & 288 & 50.0 \\
\hline Age of child (month) & 199 & 43.6 \\
\hline $0-6$ months & \multicolumn{2}{l|}{} \\
\hline $7-23$ months & 56.4 \\
\hline Religion & 406 & 89.0 \\
\hline Hindu & 31 & 6.8 \\
\hline Buddhist & 17 & 3.7 \\
\hline Muslim & 2 & .4 \\
\hline Christian & \multicolumn{2}{|l|}{} \\
\hline Family type & 57.9 \\
\hline Single & 264 & 42.1 \\
\hline Joint & 192 & 79.6 \\
\hline No. of children per household & 363 & 20.4 \\
\hline 2 or less & 93 & 11.6 \\
\hline 3 or more & 70.8 \\
\hline Main source of income & 53 & 11.6 \\
\hline Agriculture & 323 & 4.8 \\
\hline Job & 53 & 1.1 \\
\hline Business & 22 & \\
\hline Daily wages & 5 & \\
\hline Pension &
\end{tabular}

Table 2: Distribution of children based on feeding practice

\begin{tabular}{|c|c|c|c|c|}
\hline Feeding practice & Male & Female & $\chi^{2}$ & p-value \\
\hline \multicolumn{5}{|l|}{ Time of first breastfeed } \\
\hline 1 hrs after birth & $124(54.4 \%)$ & $108(47.4 \%)$ & \multirow[b]{2}{*}{2.246} & \multirow[b]{2}{*}{0.134} \\
\hline More than one hour after birth & $104(45.6 \%)$ & $120(52.6 \%)$ & & \\
\hline \multicolumn{5}{|l|}{ Colostrums feeding } \\
\hline Yes & $221(96.9 \%)$ & $225(98.7 \%)$ & \multirow[b]{2}{*}{1.636} & \multirow[b]{2}{*}{0.201} \\
\hline No & $7(3.1 \%)$ & $3(1.3 \%)$ & & \\
\hline \multicolumn{5}{|l|}{ Pre lacteal feeding } \\
\hline Yes & $30(13.2 \%)$ & $24(10.5 \%)$ & & \\
\hline No & $198(86.8 \%)$ & $204(89.5 \%)$ & 0.756 & 0.385 \\
\hline \multicolumn{5}{|l|}{\begin{tabular}{|l|} 
Frequency of breastfeeding \\
\end{tabular}} \\
\hline Less than 9 times & $103(45.8 \%)$ & $107(47.1 \%)$ & \multirow[b]{2}{*}{0.111} & \multirow[b]{2}{*}{0.739} \\
\hline More than 9 times & $123(54.4 \%)$ & $120(52.9 \%)$ & & \\
\hline \multicolumn{5}{|l|}{\begin{tabular}{|l|} 
Exclusive feeding \\
\end{tabular}} \\
\hline$<5$ month & $5(3.8 \%)$ & $83(64.8 \%)$ & \multirow[b]{2}{*}{108.193} & \multirow[b]{2}{*}{$<0.001$} \\
\hline 6 month & $128(96.2 \%)$ & $45(35.2 \%)$ & & \\
\hline \multicolumn{5}{|l|}{ Weaning practice } \\
\hline$<5$ month & $3(2.3 \%)$ & $67(52.3 \%)$ & & \\
\hline$>5$ month & $130(97.7 \%)$ & $61(47.7 \%)$ & 83.376 & $<0.001$ \\
\hline \multicolumn{5}{|c|}{ Frequency of complementary feeding } \\
\hline Less than 4 times & $70(53 \%)$ & $68(53.1 \%)$ & \multirow[b]{2}{*}{0.000} & \multirow[b]{2}{*}{0.988} \\
\hline More than 4 times & $62(47 \%)$ & $60(46.9 \%)$ & & \\
\hline
\end{tabular}

Above table presents the data on feeding practice (time of first initiation of breast milk, colostrums feeding, frequency of breast feeding, exclusive feeding and frequency of complementary feeding). The data shows that some difference by gender in feeding practices but most of these differences were not statistically significant. In our 
study $54.4 \%$ and $47.4 \%$ female were breastfed within 1 hrs after birth, there was no variation between male and female. In this study female were slightly more likely to be feed colostrums milk than male (male $96.9 \%$ and female $98.7 \%$ ) but there was statistically not significant. In our study nearly all $97.7 \%$ male were start complementary feeding at the recommended time and nearly half $47.7 \%$ of the female children were start complementary feeding at the recommended time. The association was found to be statistically significant $(\mathrm{p}<0.001)$. In this study more male were exclusively breastfed than female. The association was found to be statistically significant $(\mathrm{p}<0.001)$. In frequency of breast feeding and complementary feeding practice there were statistically not significant with gender.

Table 3: Distribution of children based on child health care during illness

\begin{tabular}{|l|l|l|l|l|}
\hline Child care and support & \multicolumn{1}{|c|}{ Male } & \multicolumn{1}{|c|}{ Female } & \multicolumn{1}{c|}{$\boldsymbol{2}$} & p-value \\
\hline \multicolumn{1}{|c|}{ Place of treatment } & & & & \\
\hline Home treatment & $4(7.7 \%)$ & $1(3 \%)$ & 1.256 & $0.740 \#$ \\
\hline Hospital & $26(50 \%)$ & $16(48.5 \%)$ & & \\
\hline PHC/HP & $4(7.7 \%)$ & $4(12.1 \%)$ & & \\
\hline Clinic & $18(34.6 \%)$ & $12(36.4 \%)$ & & \\
\hline
\end{tabular}

\# Likelihood ratio

In our study total of 85 children were suffered from different health problems among them $54.1 \%$ children were suffer from respiratory problems and most of the respondents were went to hospital for the treatment of their child during illness. Among them 50\% male and $48.5 \%$ female were treated in hospital during illness. In our study almost all children got vitamin A and vaccines. The differences were statically not significant.

Table 4: Distribution of children based on nutritional status

\begin{tabular}{|l|l|l|l|l|}
\hline \multicolumn{1}{|c|}{ Nutritional status } & \multicolumn{1}{|c|}{ Male } & \multicolumn{1}{c|}{ Female } & \multicolumn{1}{c|}{$\chi 2$} & p-value \\
\hline Stunting & $5(2.2 \%)$ & $9(3.9 \%)$ & & \\
\hline Stunted & $28(12.3 \%)$ & $23(10.1 \%)$ & 7.513 & 0.057 \\
\hline Moderately stunted & $14(6.1 \%)$ & $4(1.8 \%)$ & & \\
\hline Severely stunted & $181(79.4 \%)$ & $192(84.2 \%)$ & & \\
\hline Normal & $7(3.1 \%)$ & $8(3.5 \%)$ & & \\
\hline Wasting & $16(7 \%)$ & $14(6.1 \%)$ & 0.950 & 0.813 \\
\hline Wasted & $9(3.9 \%)$ & $13(5.7 \%)$ & & \\
\hline Moderately wasted & $196(86 \%)$ & $193(84.6 \%)$ & & \\
\hline Severely wasted & $14(6.1 \%)$ & $8(3.5 \%)$ & & \\
\hline Normal & $22(9.6 \%)$ & $14(6.1 \%)$ & 3.927 & 0.269 \\
\hline Underweight & $8(3.5 \%)$ & $8(3.5 \%)$ & & \\
\hline Underweight & $184(80.7 \%)$ & $198(86.8 \%)$ & & \\
\hline Moderately underweight &
\end{tabular}

Above table presents the prevalence of malnutrition by gender. In this study female appeared slightly more likely to be stunted than male, but the association was found to be statistically no significant. On measuring the weight for age of the under-two children using the WHO Growth Charts, male children were found to be underweight than the female children. But, the association was found o be statistically non significant. Around 14\% male and $15.3 \%$ female were wasted. However, higher percentage of female was wasted than male. The association was found to be statistically no significant.

\section{DISCUSSION}

In this study early initiation of breastfeeding within one hour after birth was found to be higher in male than female (54.4\% males and $47.4 \%$ females) which is almost similar study was conducted in rural area of Bijapur district, ${ }^{2}$ Karanatak, rural area of west Bengal ${ }^{11}$ and study conducted in tribal children. ${ }^{12}$

In this study majority of the male children were found to be fed other food than breast milk after birth than the female children (13.2\% males and $10.5 \%$ females). The study was conducted in rural area of Bijapur district, Karanatak majority of females children were found to be fed other food than breast milk after birth ${ }^{2}$ and the similar study was conducted in rural area of west Bengal. ${ }^{11}$ Reason behind of these differences may be due to different cultural practices and most of the children deliver by surgery.

In this study more female children were fed colostrums milk in compared to male children but just opposite in the study conducted in more male children were fed colostrums milk in compared to female children in the rural area of west Bengal. ${ }^{11}$ This difference may be due to maternal knowledge on colostrums feeding.

In this study nearly all male children were exclusively breastfed up to six month than female children, which is similar when compared to studies conducted in Civil Hospital Karachi, ${ }^{7}$ rural area of Bijapur district, Karanatak ${ }^{2}$ and the study conducted in rural community of Cameroon. ${ }^{13}$ In this study more male children were weaning after six months than female $(98.5 \%$ male $48.1 \%$ females) and the study conducted in rural area of Bijapur district, Karanatak more female children were weaning after six month than male children. ${ }^{2}$ This difference may be due to cultural practices.

In this study prevalence of breastfeeding was $99.3 \%$ which is higher than the study conducted in the rural community of Cameroon. ${ }^{13}$ Breastfeeding was still practiced by mother but exclusive breastfeeding was scarce. But in this study prevalence of breastfeeding and exclusive feeding is good. In this study majority of the male children were started complementary at the recommended time than female children, which is similar when compared to study conducted in eastern Ethiopia. ${ }^{12}$

In this study 85 children were suffering from illness. Among them only $5.91 \%$ ill children were treated in home and almost all were treated in health facility, no variation between male and female during illness. Similar study was conducted in rural area of Uttar Pradesh, India ${ }^{14}$ there were 
no gender differences during illness.

In this study percentage of ever vaccinated was $100 \%$ but the study conducted in Pakistan percentage of ever vaccinated was $92.8 \% .^{15}$

Nutrition plays an important role in the health and development of individuals. Adequate nutrition during the first two years of life is very important to ensure optimal, physical and mental development.

In this study more male were severely stunted than female, more female were severely wasted than male and the proportion of severely underweight is same in both male and female. Similar studies conducted in rural field practice area of Shri BM Patil Medical College. ${ }^{16}$ Male children were more malnourished than female children. This is contrary to the general belief that female children are more malnourished. ${ }^{16}$

\section{CONCLUSION}

The study revealed that, majority of the children had received breastfeeding within one hour after birth; among them more male children were started first breastfeed within one hour after birth than female children. Nearly all of the mothers had fed colostrums milk to their baby. Only few mothers had feed other food than breast milk after birth. Majority of the mothers had exclusively breastfed their children up to six months. Among them, male were more exclusively breastfed up to six months than female. This study shows the significant relationship between gender and exclusively breastfeeding. Most of the mothers weaned their male children up to six months ans for female children up to five months. Majority of the mothers fed their children less than four times a day. Most of the respondents preferred to feed high amount of energy food to both children but less consumption of protective food. In this study child care and support during illness was good and there were no any gender differences. The proportion of male and female children treated in hospital was nearly equal. Almost all child got vitamin A and Vaccines. Prevalence of stunting was found to be slightly higher than the wasting and underweight but there were no gender differences in nutritional status.

\section{REFERENCES}

1. World Health Organization: gender, equity and human right [Accessed on December, 2016] available from: http://www. who.int/gender-equity-rights/understanding/gender-definition/en/

2. Angadi MM and Jawaregowda SK. Gender discrimination in relation to breast feeding practices in rural areas of Bijapur district, Karnataka. International Journal of Contemporary Pediatrics, 2015; 2(4):340-4.

3. What is care and support [Accessed on December, 2016] available from: http://www.towerhamlets.gov.uk/lgnl/health_social_care/care_and_support/care_and_support.aspx

4. Kuntal KS, Dewan SA, Shams EA, Lars AP, and Kathleen MR. Appropriate infant feeding practices result in better growth of infants and young children in rural Bangladesh. Am J Clin Nutr, 2008 June ; 87(6):1852-1859.

5. Basu $\mathrm{S}$, Aundhakar $\mathrm{CD}$, Galgali A. Gender discrimination in relation to exclusive breast feeding practices amongst twins in rural India. IJHSR, 2014; 4(5):139-143

6. Rao S, Swathi P, Unnikrishnan B, Hegde A. Study of complementary feeding practices among mothers of children aged six months to two years-A study from coastal south India. The Australasian medical journal, 2011; 4(5):252.

7. Sohag A, Memon S. Perception, practices and factors associated with exclusive breast feeding failure. Medical channel, 2011; 17(4).

8. Shrestha SM and Malla S. Complementary feeding practices and its impact on nutritional status of under two old children in the urban area of the Kathmandu, Nepal. Journal of Nepal Health Research Council, April 2004; 2(1):1-4.

9. Kumar SS and Maruthakutti R. Understanding gender inequity in feeding practices: reference to rural Coimbatore, Tamil Nadu. International Journal of Research in Sociology and Social Anthropology, 2014; 2(1):1-8.

10. Banerjee B and Bandyopadhyay L. Gender differences in nutritional status. Indian pediatrics, 2005;42:400.

11. Pal I, Chaudhuri RN. Gender inequalities while rearing of children under 5 years in a rural area of West Bengal. Indian Journal of Community Medicine, 2007 Jul 1;32(3):215.

12. Sarkar TK, Bhattacherjee S, Mukherjee A, Saha TK, Chakraborty M, Dasgupta S. Early initiation of breast feeding in tribal children. International Journal of Community Medicine and Public Health, 2016; 3(11):3081-5.

13. Mananga MJ, Kana MM, Nolla NP, Gouado GI. Feeding practices, food and nutrition insecurity of infants and their mothers in Bangang rural community, Cameroon. Journal of Nutrition \& Food Sciences, 2014 Jan 1; 4(2):1.

14. Willis JR, Kumar V, Mohanty S, Singh P, Singh V, Baqui AH, Awasthi S, Singh JV, Santosham M, Darmstadt GL. Gender differences in perception and care-seeking for illness of newborns in rural Uttar Pradesh, India. Journal of Health, Population and Nutrition, 2009 Feb 1; 62-71.

15. Masud F and Farooq S. Gender differentials in preventive health care: Incidences and determinants among Pakistani children. Pak. J. Commer. Soc. Sci, 2012 Jul 1; 6(2):308-24.

16. Shashank KJ and Angadi MM. Gender disparity in health and nutritional status among under-five children in a rural field practice area of Shri BM Patil Medical College. International Journal of Medical Science and Public Health, 2016; 5(2):217-20. 